\title{
Investigation on graphene growth by roll-to-roll chemical vapor deposition
}

\author{
Minghao Liang ${ }^{1,2}$, Ling-Xuan Qian ${ }^{1,2}$, Yuting Hou ${ }^{1,2^{*}}$, Jun $\mathrm{Li}^{1,2}$, Changqing Shen ${ }^{1,2}$, Fangzhu Qing ${ }^{1,2,3}$ and \\ Xuesong $\mathrm{Li}^{1,2,3^{*}}$
}

\begin{abstract}
Both batch-to-batch (B2B) and roll-to-roll (R2R) processes can be used for mass production of graphene films. Because of the simplicity of equipment, the B2B process is more commonly used in laboratory research. In contrast, the $R 2 R$ process is more industrially preferred because it is easier to automate and more compatible with the subsequent transfer process. Up to now, the research on $\mathrm{R} 2 \mathrm{R}$ process has mainly focused on the design of the reactor or the loading configuration, but the in-depth understanding on the growth kinetics is lack. In this paper, we investigated the evolution of graphene growth and revealed that the graphene domain density grown by the $R 2 R$ process was larger than that by the $B 2 B$ process with the same reaction parameters, which was attributed to different reaction profiles between the two processes. Furthermore, the defective graphene could be healed with elongated reaction time. With the optimized $R 2 R$ process, graphene films with quality comparable to those grown by conventional B2B process could be achieved. Our research will promote the development of the mass-production technique for graphene films.
\end{abstract}

Keywords: graphene, chemical vapor deposition, roll to roll, kinetics

\section{INTRODUCTION}

Graphene has rapidly become the international research frontier and hot spot since its rediscovery in 2004 because of its excellent properties and promising applications [1]. Chemical vapor deposition (CVD) of graphene on $\mathrm{Cu}$ has become the main technique for the production of large-area graphene films [2]. Both batch-to-batch (B2B) and roll-to-roll (R2R) processes can be used for mass production [3]. Because of the simplicity of equipment, the $\mathrm{B} 2 \mathrm{~B}$ process is more commonly adopted in laboratory research, with the purpose of studying the graphene growth mechanism and kinetics, optimizing the process for the improvement of film quality, and developing the growth technique for single crystal $[3,4]$. In contrast, the $\mathrm{R} 2 \mathrm{R}$ process is more industrially preferred because it is easier to automate and more compatible with the subsequent transfer process [5-10]. Hesjedal et al. [11] grew graphene on $\mathrm{Cu}$ with an $\mathrm{R} 2 \mathrm{R}$ atmospheric pressure CVD (APCVD) process at $1000^{\circ} \mathrm{C}$ for the first time. However, the defect density was very high as indicated by
Raman spectroscopy characterization. Yamada et al. $[12,13]$ used microwave plasma CVD (MWPCVD) to grow graphene at a low temperature down to $400^{\circ} \mathrm{C}$, but the film was also defective. Kobayashi et al. [7] used an R2R low-pressure CVD (LPCVD) system to grow a 100-m-long graphene film with improved quality through Joule heating of the $\mathrm{Cu}$ foil. Polsen et al. [14] used a concentric tube reactor to improve the production efficiency. Zhong et al. [15] designed an R2R CVD system with the end open to the ambient, targeting to enable the inline integration of graphene CVD for industrial R2R production. With the use of single-crystalline $\mathrm{Cu}(111)$ substrate, $\mathrm{Xu}$ et al. [16] achieved large-area and high-quality graphene films with single crystallinity. However, so far, the research on the R2R process has mainly focused on the design of the reactor or the loading configuration, but the in-depth understanding on the growth kinetics is rare.

Here, we investigated the evolution of graphene growth and revealed that the graphene domain density grown by the $\mathrm{R} 2 \mathrm{R}$ process was larger than that by the $\mathrm{B} 2 \mathrm{~B}$ process with the same reaction parameters (e.g., temperature, pressure and atmosphere). We attribute it to the different reaction profiles between the two processes. In the $\mathrm{B} 2 \mathrm{~B}$ process, the reaction of graphene synthesis was triggered by introducing methane at the desired temperature. There was no graphene nucleation and growth during the process of heating up in which no carbon precursor was introduced in an uncontaminated system [17]. On the other hand, in the $\mathrm{R} 2 \mathrm{R}$ process, graphene nucleation could actually start at a lower temperature during the process of heating up, which resulted in a higher domain density [18]. This is due to the fact that the reaction atmosphere has already been established when the substrate enters the reaction zone from the cold region to the hot region (i.e., the process of heating up). Furthermore, we demonstrated that graphene films with the quality comparable to those grown by conventional $\mathrm{B} 2 \mathrm{~B}$ process could be achieved with the optimized $\mathrm{R} 2 \mathrm{R}$ process. Our research will promote the development of the mass-production technique for graphene films.

\section{EXPERIMENTAL SECTION}

\section{R2R equipment}

Fig. 1a is the schematic diagram of the R2R CVD equipment. The reaction chamber was a quartz tube with the outer diameter

\footnotetext{
${ }^{1}$ State Key Laboratory of Electronic Thin Films and Integrated Devices, University of Electronic Science and Technology of China, Chengdu 610054, China

${ }^{2}$ School of Electronic Science and Engineering, University of Electronic Science and Technology of China, Chengdu 610054, China

${ }^{3}$ Shenzhen Institute for Advanced Study, University of Electronic Science and Technology of China, Shenzhen 518110, China

*Corresponding authors (emails: lxs@uestc.edu.cn (Li X); treatsure_fishyuty@163.com (Hou Y))
} 

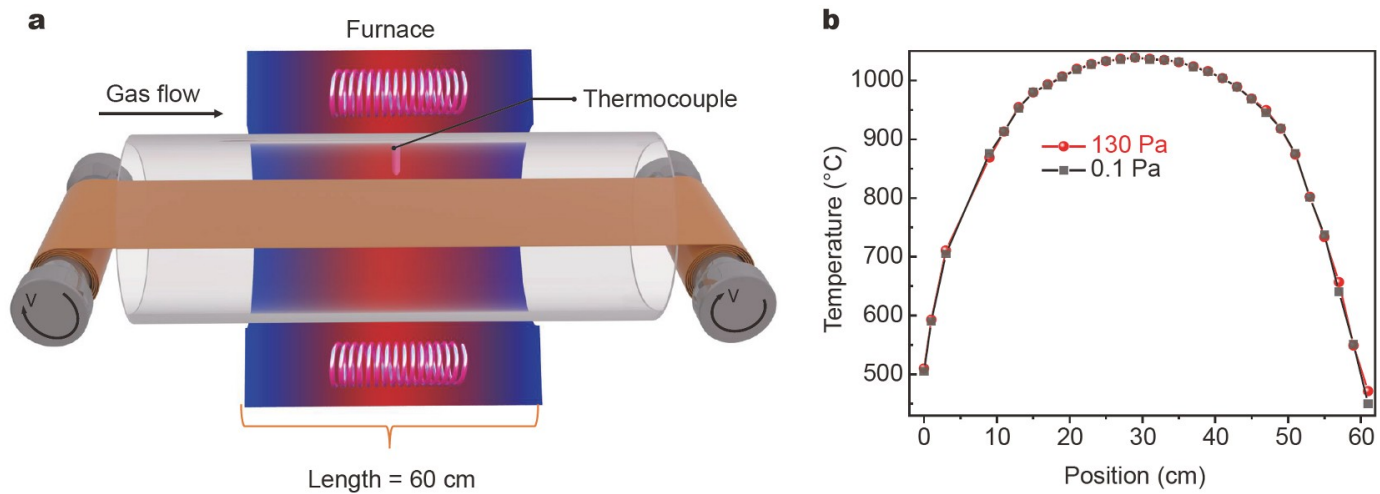

Figure 1 (a) Schematics of the R2R CVD equipment. The length of the furnace is $60 \mathrm{~cm}$. (b) Temperature profiles inside the quartz tube under vacuum condition $<0.1 \mathrm{~Pa}$ and under $\sim 130 \mathrm{~Pa}$ with $400 \mathrm{sccm}\left(1 \mathrm{sccm}=1 \mathrm{~mL} \mathrm{~min}^{-1}\right) 5 \mathrm{vol} \% \mathrm{H}_{2} / \mathrm{Ar}$ atmosphere, respectively, corresponding to a reading value of $1030^{\circ} \mathrm{C}$ of the furnace.

of 4 inch $(1$ inch $=2.54 \mathrm{~cm})$, heated by a 60 -cm-long split tube furnace. The background pressure of the reaction chamber was about $<0.1 \mathrm{~Pa}$. The thermocouple of the furnace was located at the center of the top part of the furnace, almost touching the quartz tube. Another set of $4 \mathrm{~K}$-type thermocouples were used to measure the reaction temperature profile along with the reaction chamber (Fig. S1). Fig. 1b shows the temperature profiles either under vacuum condition $<0.1 \mathrm{~Pa}$ or under $\sim 130 \mathrm{~Pa}$ with $400 \mathrm{sccm}$ (standard cubic centimeter per minute) $5 \mathrm{vol} \% \mathrm{H}_{2} / \mathrm{Ar}$ atmosphere, corresponding to a reading temperature of $1030^{\circ} \mathrm{C}$ of the furnace. It can be seen that there is no obvious difference between the two cases, indicating that the reaction atmosphere has almost no effect on the temperature profiles.

\section{Graphene synthesis}

Graphene synthesis was conducted in LPCVD. The $\mathrm{Cu}$ strip (Dongguan Lidong metal foil Co., Ltd., model T2) with a $50-\mu \mathrm{m}$ thickness, a $75-\mathrm{mm}$ width, and a purity of $99.9 \%$ was pre-treated by annealing at $1030^{\circ} \mathrm{C}$, with a $3.5 \mathrm{~mm} \mathrm{~min}^{-1}$ motion speed through the heating zone, in $400 \mathrm{sccm} 5 \mathrm{vol} \% \mathrm{H}_{2} / \mathrm{Ar}$ atmosphere under $\sim 130 \mathrm{~Pa}$. No other pre-cleaning process was performed. For the R2R growth, the atmosphere was $400 \mathrm{sccm} 5$ vol\% $\mathrm{H}_{2} / \mathrm{Ar}$ and $10-100 \mathrm{sccm} 1 \mathrm{vol} \% \mathrm{CH}_{4} / \mathrm{Ar}$ with a pressure of $\sim 140 \mathrm{~Pa}$. The motion speed was 3.5 or $6.6 \mathrm{~mm} \mathrm{~min}^{-1}$. To terminate the reaction, the motion of $\mathrm{Cu}$ substrate was stopped and the furnace was shut off right away and opened up, followed with a fan blowing to the hot quartz tube for quick cooling down the $\mathrm{Cu}$ substrate.

For the $\mathrm{B} 2 \mathrm{~B}$ process as a control, $\mathrm{Cu}$ substrate was located at the center of heating zone. It went through the same synthesis atmosphere but without moving, and cooled down in the same way as that of the interrupted $\mathrm{R} 2 \mathrm{R}$ process.

\section{Graphene transfer}

The as-grown graphene films were transferred onto 285-nm $\mathrm{SiO}_{2} / \mathrm{Si}$ substrates by the polymethyl methacrylate (PMMA)assisted wet transfer method [19]. PMMA (3 wt\%, average molecular weight 550,000, dissolved in ethyl lactate) was spinning coated on the upside of the graphene-coated $\mathrm{Cu}$ foil at $3000 \mathrm{r} \mathrm{min}^{-1}$ for $32 \mathrm{~s}$ and $1000 \mathrm{r} \mathrm{min}^{-1}$ for $12 \mathrm{~s}$, followed with baking at $100^{\circ} \mathrm{C}$ for $2 \mathrm{~min}$. $\mathrm{Cu}$ was etched by $1 \mathrm{~mol} \mathrm{~L}^{-1} \mathrm{FeCl}_{3}$ aqueous solution with $5 \% \mathrm{HCl}$. PMMA was dissolved with acetone after the graphene film was transferred onto the $\mathrm{SiO}_{2} / \mathrm{Si}$ wafer.

\section{Characterizations}

Characterizations were performed with optical microscopy (Nikon, LV100ND), Raman spectroscopy (Renishaw, Invia Reflex, laser wave length of $532 \mathrm{~nm}$ ), the van der Pauw-Hall (VDP-H) measurement (ECOPIA HMS-5000 Hall), and scanning electron microscopy (SEM, Navo NanoSEM450).

\section{RESULTS AND DISCUSSION}

In the $\mathrm{R} 2 \mathrm{R}$ process, since the whole $\mathrm{Cu}$ strip experienced the same reaction process, when the reaction was interrupted and the cooling speed was quick enough, the growth of graphene could be considered being frozen, and thus the positions of $\mathrm{Cu}$ foil in the reaction zone corresponded to the evolution stages of graphene nucleation and growth. That is, in our designed system, the closer of the $\mathrm{Cu}$ substrate to the left edge of furnace, the more initial stage of the reaction, while the closer to the right edge, the more accomplishment of graphene growth. Therefore, the evolution scenario of graphene nucleation and growth can be achieved by analyzing the $\mathrm{Cu}$ substrate along with the moving direction.

Fig. 2 shows the SEM images of the graphene grown with a motion speed of $3.5 \mathrm{~mm} \mathrm{~min}^{-1}$ and different $\mathrm{CH}_{4} / \mathrm{Ar}$ flow rates. In the case of $50 \mathrm{sccm} \mathrm{CH}_{4} / \mathrm{Ar}$ (Fig. 2a), graphene nucleation started at the position of $10 \mathrm{~cm}$, corresponding to a temperature of $889^{\circ} \mathrm{C}$. No graphene was found at the position of $8 \mathrm{~cm}$ and afterward (position $<8 \mathrm{~cm}$ ). By moving forward (position $>10 \mathrm{~cm}$ ), both nucleation density and domain size increased until the adjacent domains merged into islands and eventually a continuous film. With a higher methane flow rate of $100 \mathrm{sccm}$, graphene nucleation could even start at the position of $1 \mathrm{~cm}$ at $593^{\circ} \mathrm{C}$ (Fig. 2b), lower than that previously reported [20]. In contrast, both nucleation and growth were suppressed with a lower methane flow rate of $10 \mathrm{sccm}$ (Fig. 2c), where the graphene nucleation started at a higher temperature at $18 \mathrm{~cm}$, which was consistent with previous reports $[21,22]$.

Fig. 3 shows the evolutions of coverage, domain density, and domain size of graphene with different $\mathrm{CH}_{4} / \mathrm{Ar}$ flow rates, and the statistical results come from three different regions for each position (or temperature). As shown in Fig. 3b, graphene domain density increases first and then decreases. The decrease may be due to the fault counting on graphene islands merged 

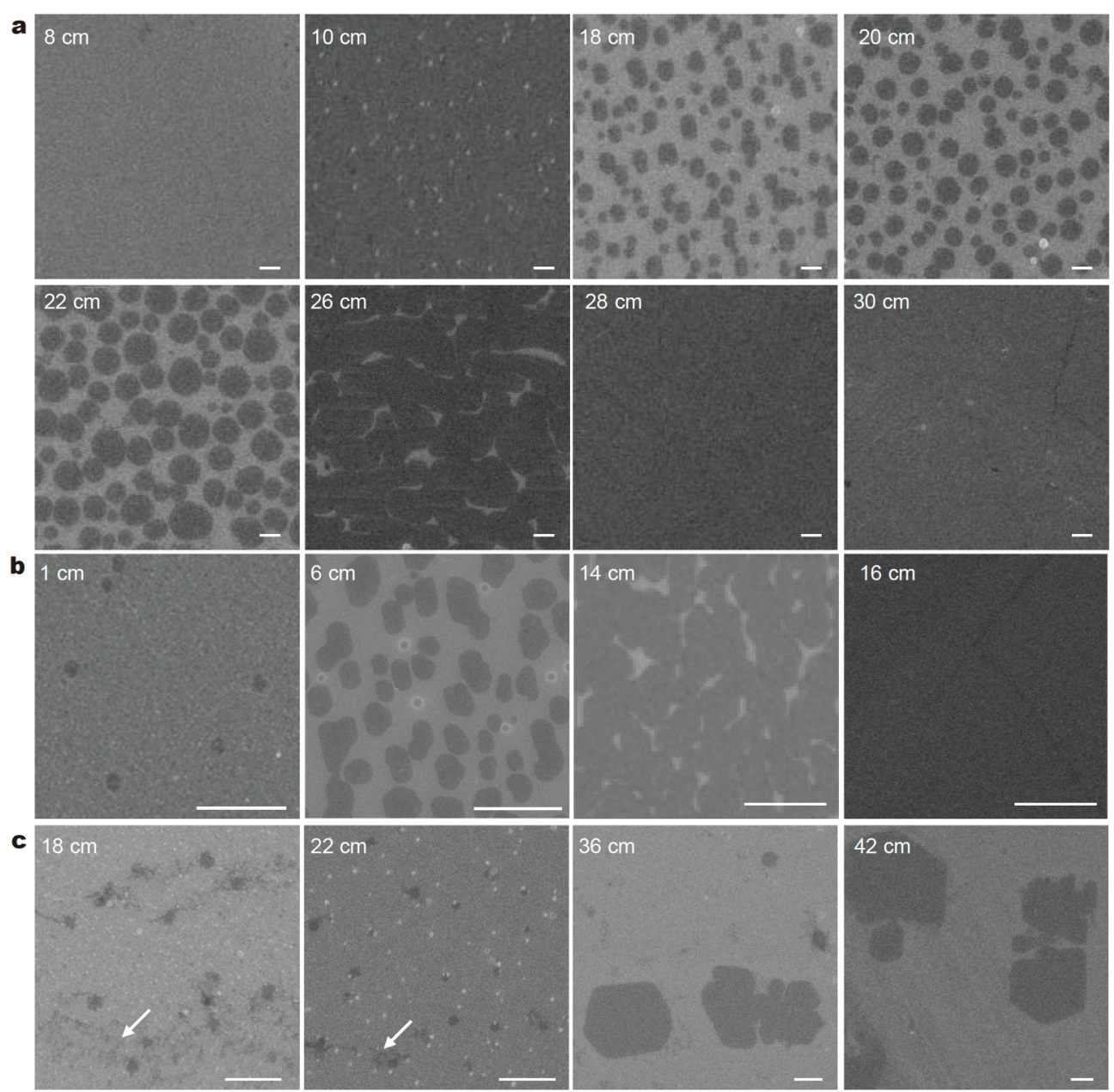

Figure $2 \mathrm{SEM}$ images of the as-grown graphene on $\mathrm{Cu}$ with a motion speed of $3.5 \mathrm{~mm} \mathrm{~min}^{-1}$ and (a) $50 \mathrm{sccm},(\mathrm{b}) 100 \mathrm{sccm}$, and $(\mathrm{c}) 10 \mathrm{sccm} \mathrm{CH} / \mathrm{Ar}$, respectively. The labels on each image indicate the sample positions. The white spots in some of the SEM images are impurity particles. The white arrow refers to the amorphous carbon on the $\mathrm{Cu}$ surface. Scale bar is $1 \mu \mathrm{m}$.

from several domains. The competing growth between domains (some domains may swallow up others) can also result in the decrease of domains. As a result, the corresponding sizes in Fig. 3c may be partly over evaluated. In addition, when the methane flow was extremely low (e.g., $10 \mathrm{sccm}$ ), the nucleation density saturated quickly and then kept almost constant even though there was still a large fraction of $\mathrm{Cu}$ exposed while the domains kept growing with time extension. This may be attributed to the lower energy barrier for growth than that for nucleation [23]. Initially, methane molecules adsorb onto $\mathrm{Cu}$ surface and decompose into active species. Once the concentration of the active species reaches the criteria for graphene nucleation, the nucleation starts and the accumulated active species are depleted quickly, leading to a decrease of the active species. With the presence of graphene nuclei, graphene can grow with a lower concentration of the active species since the critical concentration for growth is lower than that for nucleation. If the methane flow rate is high, it can provide enough active species to maintain their concentration always higher than the critical nucleation concentration and thus the domain density increases with time as long as there is enough exposed $\mathrm{Cu}$. On the other hand, when the methane flow rate is low, the supply of active species is slow, which may be enough for gra- phene growth but not able to accumulate to a higher concentration again for the nucleation. Nevertheless, with more methane, the graphene nucleation/growth was faster, and/or the nucleation/growth temperature was lower.

Fig. 4a, b show the typical optical microscopy images of the transferred isolated graphene domains and continuous graphene films with $100 \mathrm{sccm} \mathrm{CH}_{4} / \mathrm{Ar}$, respectively. Fig. 4c shows the typical Raman spectra of graphene at different positions with $100 \mathrm{sccm} \mathrm{CH} / \mathrm{Ar}$. Raman spectra for those with 50 and $10 \mathrm{sccm}$ $\mathrm{CH}_{4} / \mathrm{Ar}$ are shown in Fig. S2. The single Lorentz 2D band indicates the graphene is monolayer [24] and all optical microscopy and SEM results indicate the films are uniform in thickness. Fig. $4 \mathrm{~d}$, e show the intensity ratio of $\mathrm{D}$ band to $\mathrm{G}$ band, $I_{\mathrm{D}} / I_{\mathrm{G}}$, an indication of defect density in graphene $[25,26]$, $v s$. graphene coverage and position, respectively. It can be seen that $I_{\mathrm{D}} / I_{\mathrm{G}}$ decreases along the moving direction. Since the laser spot size is about $1 \mu \mathrm{m}$, very close to the domain size, the high D peak for the initial stage most likely results from the defective nucleation center and edges $[25,27,28]$. It could be also due to the low temperature during early nucleation and growth since lower temperature tends to generate more defects $[20,29]$. With the substrate moving forward into the hot region, the defect density decreases due to the merging of domains and the self- 


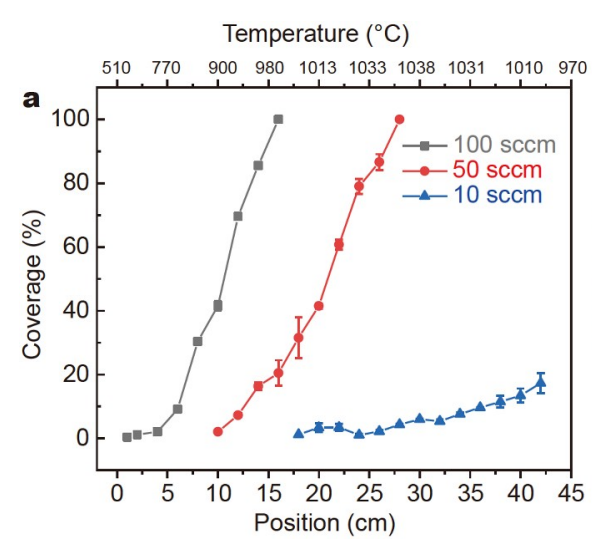

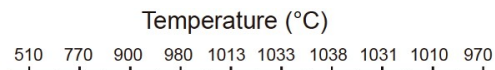

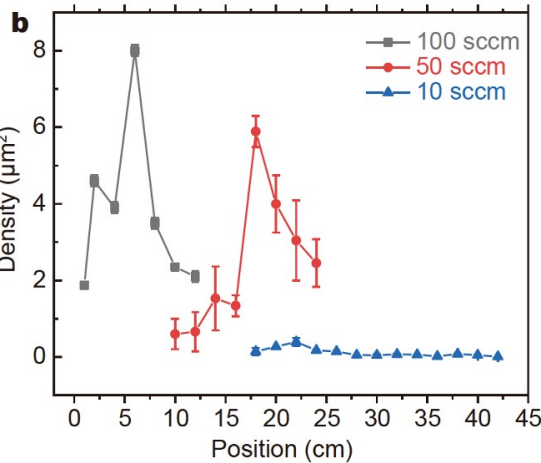

Temperature $\left({ }^{\circ} \mathrm{C}\right)$

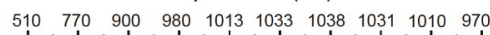

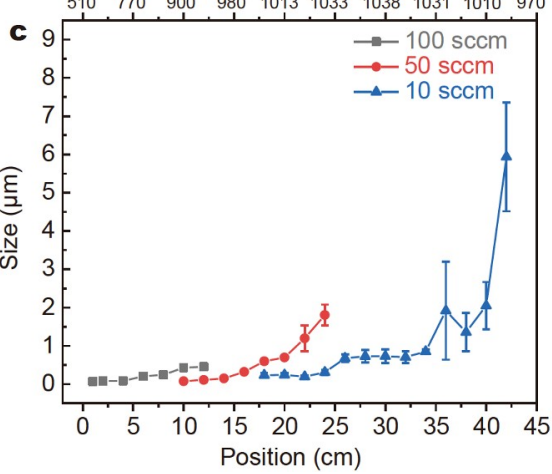

Figure 3 The evolutions of (a) coverage, (b) domain density, and (c) domain size of graphene with different $\mathrm{CH}_{4} / \mathrm{Ar}_{\text {flow }}$ rates.
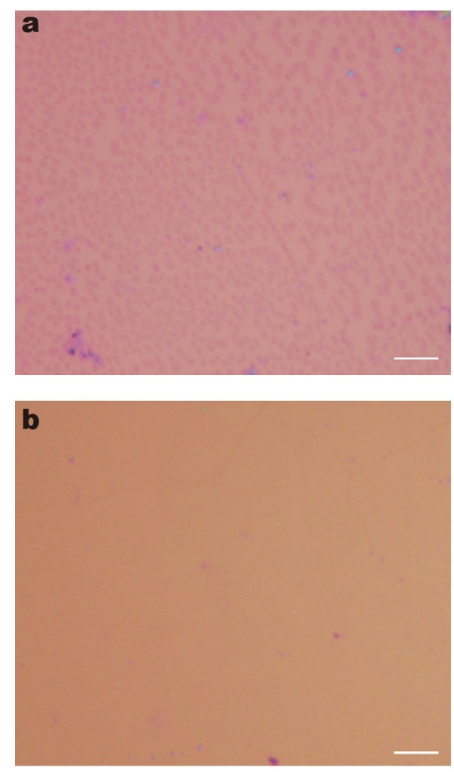
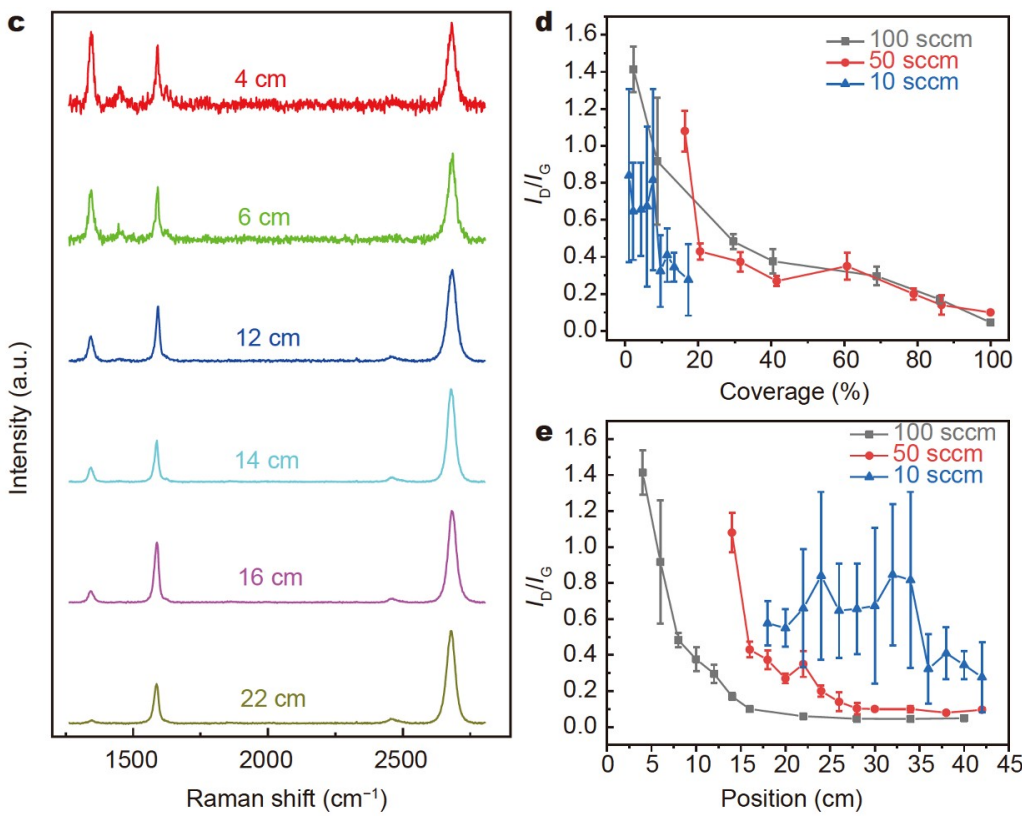

Figure 4 Optical microscopy and Raman spectroscopy characterizations. The typical optical microscopy images of the transferred (a) isolated graphene domains (position $\sim 10 \mathrm{~cm}$ ) and (b) continuous graphene films (position $\sim 20 \mathrm{~cm}$ ) under $100 \mathrm{sccm} \mathrm{CH}_{4} / \mathrm{Ar}$, respectively. Scale bar is $10 \mu \mathrm{m}$. (c) The typical Raman spectra of graphene from different positions with $100 \mathrm{sccm} \mathrm{CH}_{4} / \mathrm{Ar}$ and $I_{\mathrm{D}} / I_{\mathrm{G}} v s$. (d) graphene coverage and (e) position, respectively. The statistical result was from three different regions at each position.

healing at high temperature with elongated time. It should be noted that although the domain size of graphene with $10 \mathrm{sccm}$ $\mathrm{CH}_{4} / \mathrm{Ar}$ is much larger than that of the other two samples, it is also the most defective. On the other hand, the final $I_{\mathrm{D}} / I_{\mathrm{G}}$ value of the graphene with $100 \mathrm{sccm} \mathrm{CH} / \mathrm{Ar}$ is a little bit smaller than that with $50 \mathrm{sccm} \mathrm{CH}_{4} / \mathrm{Ar}$. This may be due to the interplay between the growth and etching agents. With less growth agents, the as-grown graphene tends to be etched while more growth agents may benefit healing the defective graphene.

Furthermore, the VDP-H measurement was used to evaluate the electrical transport performance of complete films. In VDP$\mathrm{H}$ measurement, the mobility is dependent on the carrier density that may differ a lot for different samples due to the uncontrolled natural doping, and thus the measured mobility needs to be normalized to a fixed carrier density for a fair comparison [30]. Fig. 5a shows the mobility normalized to the carrier density of $1 \times 10^{12} \mathrm{~cm}^{-2}$ and Fig. $5 \mathrm{~b}$ shows the measured sheet resis- tance. Note that although graphene grown with $100 \mathrm{sccm} \mathrm{CH}_{4} /$ Ar flow has a higher domain density and more domain boundaries, it has better electrical transport performance. This may be explained with the fact that domain boundary is not the only defect affecting graphene properties. Defects within domains also deteriorate graphene. As aforementioned, more growth agents may benefit healing defective graphene and thus reducing the defect density either within domains or domain boundaries, providing higher quality of graphene. However, too much growth agents or too high $\mathrm{C} / \mathrm{H}$ ratio may lead to the growth of graphene adlayers as reported in the literature [22,3134] and also demonstrated in present work (Fig. S3). Therefore, there is an upper limit of the growth agents or the $\mathrm{C} / \mathrm{H}$ ratio for the optimal graphene synthesis.

Since lower-temperature reaction leads to higher domain density and more defects, $\mathrm{Cu}$ substrate should pass through the transition zone as quickly as possible, i.e., with a higher motion 
speed. The evolution of graphene growth with $50 \mathrm{sccm} \mathrm{CH}_{4} / \mathrm{Ar}$ at 3.5 and $6.6 \mathrm{~mm} \mathrm{~min}^{-1}$ was compared in Fig. 6. Some typical SEM images for graphene with $6.6 \mathrm{~mm} \mathrm{~min}^{-1}$ motion speed are shown in Fig. S4a and some Raman spectra are shown in Fig. S4b. As expected, with a higher substrate motion speed, graphene started to nucleate at a higher temperature region and the maximum nucleation density is smaller while the growth was incomplete as the total growth time was shortened as well. The decrease of nucleation density did not reduce the defect density, which might be also because of the shorter growth time in the meantime (Fig. 6c).

To compare with the $\mathrm{B} 2 \mathrm{~B}$ process, the conventional graphene growth with $100 \mathrm{sccm} \mathrm{CH}_{4} / \mathrm{Ar}$ was conducted (Fig. S5). Note that during the $\mathrm{R} 2 \mathrm{R}$ process, the reaction temperature on a site of the substrate changes with its motion while for the static substrate in the $\mathrm{B} 2 \mathrm{~B}$ process the reaction temperature is constant. In the current $\mathrm{B} 2 \mathrm{~B}$ process, a growth time of 60 min was used, which was close to the time for the substrate passing through the $\sim 20 \mathrm{~cm}$ central hot zone at the speed of $3.5 \mathrm{~mm} \mathrm{~min} \mathrm{~m}^{-1}$ in the $\mathrm{R} 2 \mathrm{R}$ process. The domain size was about $8 \mu \mathrm{m}$ (Fig. S6a), much larger than that by R2R in the same condition. The conventional CVD graphene has a high coverage of adlayers (Fig. S6b), indicating that the current parameters are not optimized for monolayer graphene. Nevertheless, the optimized R2R graphene showed comparable quality in terms of defect density and electrical transport performance with the conventional graphene grown both in the same equipment (Fig. S6c-e) and in another equipment with optimized parameters for monolayer graphene [30], and better than other reported polycrystalline R2R graphene [7,11-15]. The high quality of R2R graphene in this work could be attributed to our optimized parameters, e.g., a higher temperature, an appropriate methane concentration, and enough growth time due to the low motion speed. It is expected that a longer heating zone will be better with the simultaneous improvement of quality and production throughput if the substrate can move faster so as to shorten the time for passing the low temperature region without the sacrifice of reaction time.

Another issue should be mentioned is the effect of the tensile strain of $\mathrm{Cu}$. The $\mathrm{Cu}$ strip is dragged to move and thus is strained, which is another difference from the conventional static growth. Microcracks have been observed on the as-grown $\mathrm{R} 2 \mathrm{R}$ graphene, which was attributed to the significant plastic deformation of $\mathrm{Cu}$ at high temperatures [7]. However, no such kind of cracks were observed from our R2R graphene (Fig. S7). The good electrical transport performance of our graphene (Fig. 5) also indicates its good continuity. This may be because we use thicker and narrower $\mathrm{Cu}$ strips $(50 \mu \mathrm{m}$ thick and $75 \mathrm{~mm}$ wide) than that reported ( $36 \mu \mathrm{m}$ thick and $230 \mathrm{~mm}$ wide) [7]). Thicker $\mathrm{Cu}$ is stiffer. On the other hand, a wider strip will lead to more uneven strain, resulting in more buckling [35]. From Fig. S8, it can be seen that our $\mathrm{Cu}$ foil is actually very flat without
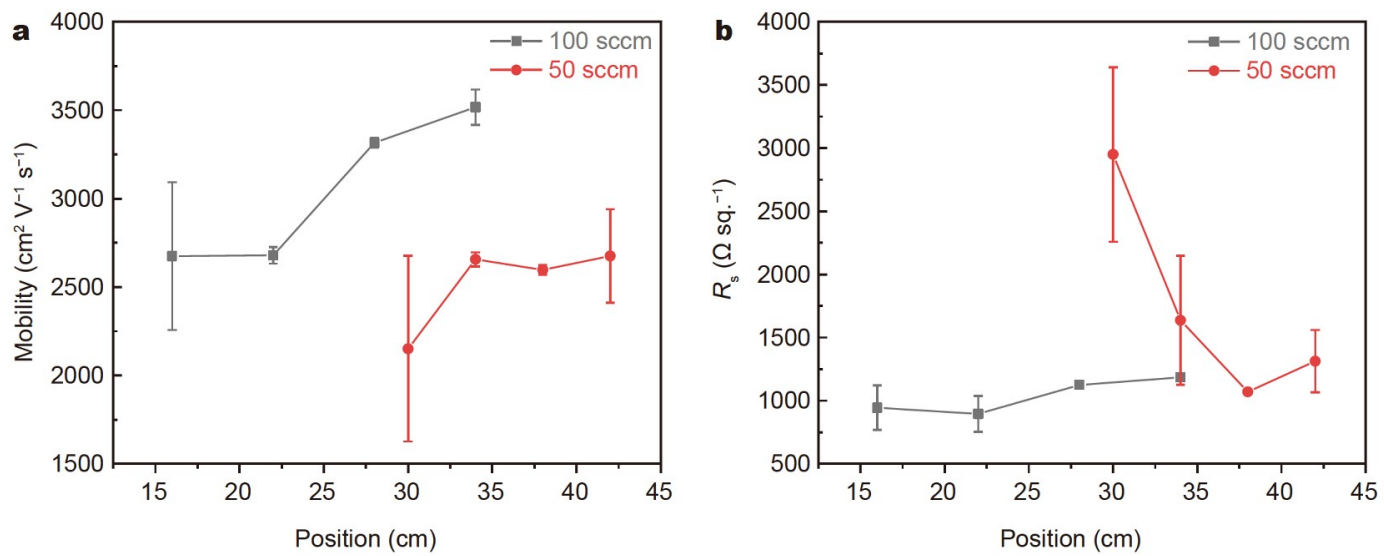

Figure 5 Plots of (a) the normalized carrier mobilities at the carrier density of $1 \times 10^{12} \mathrm{~cm}^{-2}$ and (b) the sheet resistance relative to positions with the $\mathrm{CH}_{4} / \mathrm{Ar}$ flow rates of 100 and $50 \mathrm{sccm}$. The statistical results were from three different regions at each position.
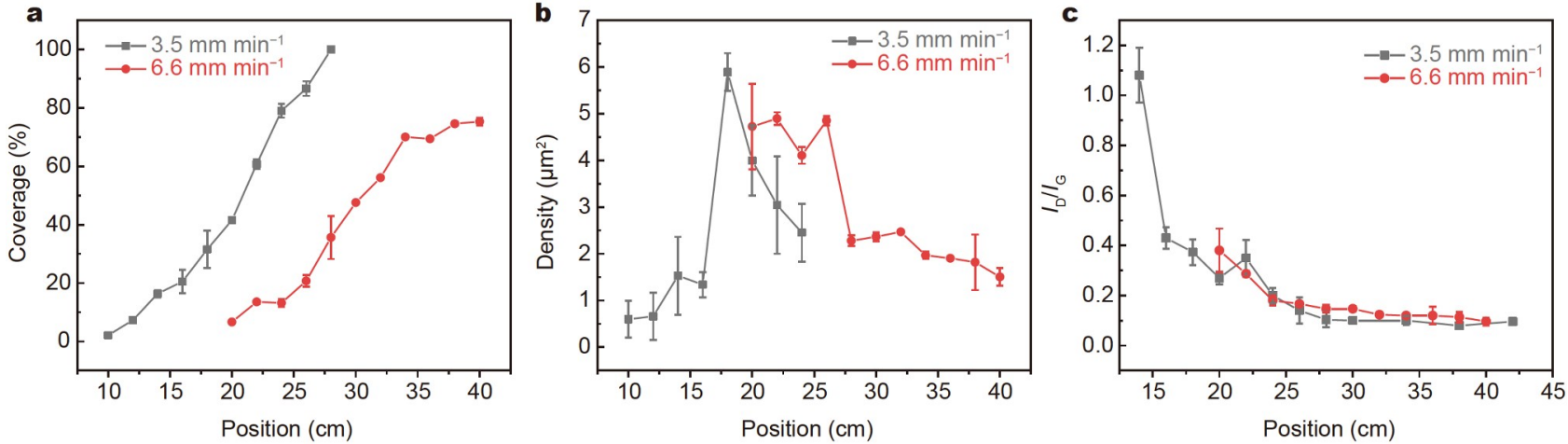

Figure 6 Evolution of (a) coverage, (b) domain density, and (c) $I_{\mathrm{D}} / I_{\mathrm{G}}$ with two different motion speeds. The statistical results were from three different regions at each position. 
significant deformation. It should be noted that well aligned rollers are also crucial for even stress so as to suppress the deformation of $\mathrm{Cu}$.

In addition, since hot $\mathrm{Cu}$ has lower Young's modulus than cold $\mathrm{Cu}$, when graphene grown on hot $\mathrm{Cu}$ moves out of the reaction zone and cools down, the tensile strain decrease of $\mathrm{Cu}$ results in more compress strain to graphene other than that introduced by thermal effect. However, a rough calculation indicates that this compress strain is very small and can be neglected (see Supplementary information for details).

\section{CONCLUSIONS}

In summary, we comprehensively investigated the kinetics of graphene nucleation and growth in the $\mathrm{R} 2 \mathrm{R}$ process. The domain size of R2R graphene was smaller than that of conventional CVD graphene, which could be attributed to different heating manners of the substrate in the two processes. In the conventional process (or the $\mathrm{B} 2 \mathrm{~B}$ process), there was no carbon precursor in the stage of heating up. In contrast, the substrate was heated up in the early-established reaction atmosphere, and graphene may nucleate and grow at a lower temperature in the $\mathrm{R} 2 \mathrm{R}$ process. The defective graphene can be healed with the extension of reaction time. In addition, we also studied the effects of parameters on graphene film quality, including methane flow rate and substrate motion speed. With our optimized parameters, the graphene films with the quality as good as the conventional CVD graphene can be realized.

\section{Received 14 July 2021; accepted 30 September 2021;}

published online 18 November 2021

1 Novoselov KS, Fal'ko VI, Colombo L, et al. A roadmap for graphene. Nature, 2012, 490: 192-200

2 Li X, Cai W, An J, et al. Large-area synthesis of high-quality and uniform graphene films on copper foils. Science, 2009, 324: 1312-1314

3 Lin L, Deng B, Sun J, et al. Bridging the gap between reality and ideal in chemical vapor deposition growth of graphene. Chem Rev, 2018, 118: 9281-9343

4 Li X, Colombo L, Ruoff RS. Synthesis of graphene films on copper foils by chemical vapor deposition. Adv Mater, 2016, 28: 6247-6252

5 Chandrashekar BN, Deng B, Smitha AS, et al. Roll-to-roll green transfer of CVD graphene onto plastic for a transparent and flexible triboelectric nanogenerator. Adv Mater, 2015, 27: 5210-5216

6 Deng B, Hsu PC, Chen G, et al. Roll-to-roll encapsulation of metal nanowires between graphene and plastic substrate for high-performance flexible transparent electrodes. Nano Lett, 2015, 15: 4206-4213

7 Kobayashi T, Bando M, Kimura N, et al. Production of a 100-m-long high-quality graphene transparent conductive film by roll-to-roll chemical vapor deposition and transfer process. Appl Phys Lett, 2013, 102: 023112

8 Jang B, Kim CH, Choi ST, et al. Damage mitigation in roll-to-roll transfer of CVD-graphene to flexible substrates. 2D Mater, 2017, 4: 024002

9 Bae S, Kim H, Lee Y, et al. Roll-to-roll production of 30-inch graphene films for transparent electrodes. Nat Nanotech, 2010, 5: 574-578

10 Juang ZY, Wu CY, Lu AY, et al. Graphene synthesis by chemical vapor deposition and transfer by a roll-to-roll process. Curr Alzheimer Resbon, 2010, 48: 3169-3174

11 Hesjedal T. Continuous roll-to-roll growth of graphene films by chemical vapor deposition. Appl Phys Lett, 2011, 98: 133106

12 Yamada T, Ishihara M, Hasegawa M. Large area coating of graphene at low temperature using a roll-to-roll microwave plasma chemical vapor deposition. Thin Solid Films, 2013, 532: 89-93

13 Yamada T, Ishihara M, Kim J, et al. A roll-to-roll microwave plasma chemical vapor deposition process for the production of $294 \mathrm{~mm}$ width graphene films at low temperature. Curr Alzheimer Resbon, 2012, 50: 2615-2619

14 Polsen ES, McNerny DQ, Viswanath B, et al. High-speed roll-to-roll manufacturing of graphene using a concentric tube CVD reactor. Sci Rep, 2015, 5: 10257

15 Zhong G, Wu X, D'Arsie L, et al. Growth of continuous graphene by open roll-to-roll chemical vapor deposition. Appl Phys Lett, 2016, 109: 193103

$16 \mathrm{Xu}$ X, Zhang Z, Dong J, et al. Ultrafast epitaxial growth of metre-sized single-crystal graphene on industrial Cu foil. Sci Bull, 2017, 62: 10741080

17 Qing F, Jia R, Li BW, et al. Graphene growth with 'no' feedstock. 2D Mater, 2017, 4: 025089

18 Kim HK, Mattevi C, Calvo MR, et al. Activation energy paths for graphene nucleation and growth on $\mathrm{Cu}$. ACS Nano, 2012, 6: 3614-3623

19 Qing F, Zhang Y, Niu Y, et al. Towards large-scale graphene transfer. Nanoscale, 2020, 12: 10890-10911

20 Li Z, Wu P, Wang C, et al. Low-temperature growth of graphene by chemical vapor deposition using solid and liquid carbon sources. ACS Nano, 2011, 5: 3385-3390

21 Li X, Magnuson CW, Venugopal A, et al. Graphene films with large domain size by a two-step chemical vapor deposition process. Nano Lett, 2010, 10: 4328-4334

22 Shen C, Yan X, Qing F, et al. Criteria for the growth of large-area adlayer-free monolayer graphene films by chemical vapor deposition. J Materiomics, 2019, 5: 463-470

23 Wu T, Zhang X, Yuan Q, et al. Fast growth of inch-sized single-crystalline graphene from a controlled single nucleus on $\mathrm{Cu}-\mathrm{Ni}$ alloys. Nat Mater, 2016, 15: 43-47

24 Wu JB, Lin ML, Cong X, et al. Raman spectroscopy of graphene-based materials and its applications in related devices. Chem Soc Rev, 2018, 47: $1822-1873$

25 Lee T, Mas'ud FA, Kim MJ, et al. Spatially resolved Raman spectroscopy of defects, strains, and strain fluctuations in domain structures of monolayer graphene. Sci Rep, 2017, 7: 16681

26 Ferrari AC. Raman spectroscopy of graphene and graphite: Disorder, electron-phonon coupling, doping and nonadiabatic effects. Solid State Commun, 2007, 143: 47-57

27 Banhart F, Kotakoski J, Krasheninnikov AV. Structural defects in graphene. ACS Nano, 2011, 5: 26-41

28 Yazyev OV, Louie SG. Topological defects in graphene: Dislocations and grain boundaries. Phys Rev B, 2010, 81: 195420

29 Yoon H, Shin DS, Kim TG, et al. Facile synthesis of graphene on $\mathrm{Cu}$ nanowires via low-temperature thermal CVD for the transparent conductive electrode. ACS Sustain Chem Eng, 2018, 6: 13888-13896

30 Qing F, Shu Y, Qing L, et al. A general and simple method for evaluating the electrical transport performance of graphene by the van der Pauw-Hall measurement. Sci Bull, 2018, 63: 1521-1526

31 Bhaviripudi S, Jia X, Dresselhaus MS, et al. Role of kinetic factors in chemical vapor deposition synthesis of uniform large area graphene using copper catalyst. Nano Lett, 2010, 10: 4128-4133

32 Lee K, Ye J. Significantly improved thickness uniformity of graphene monolayers grown by chemical vapor deposition by texture and morphology control of the copper foil substrate. Curr Alzheimer Resbon, 2016, 100: 441-449

33 Regmi M, Chisholm MF, Eres G. The effect of growth parameters on the intrinsic properties of large-area single layer graphene grown by chemical vapor deposition on $\mathrm{Cu}$. Curr Alzheimer Resbon, 2012, 50: 134-141

34 Kidambi PR, Ducati C, Dlubak B, et al. The parameter space of graphene chemical vapor deposition on polycrystalline $\mathrm{Cu}$. J Phys Chem C, 2012, 116: 22492-22501

35 Roisum DR. The mechanics of wrinkling. Tappi J, 1996, 79: 217-226

Acknowledgements This work was supported by the National Natural Science Foundation of China (51772043 and 51802036), and Shenzhen Science and Technology Program ((2021)105). 
Author contributions Li X and Hou Y designed the experiments. Qing F and Qian LX designed part of the experiments. Liang M performed graphene growth and transfer, Raman spectroscopy characterization, and data statistics; Hou Y performed SEM characterization; Shen C drew the schematics; Liang M, Hou Y, and Li X wrote the manuscript. All authors discussed and commented on the manuscript.

Conflict of interest The authors declare that they have no conflict of interest.

Supplementary information Experimental details and supporting data are available in the online version of the paper.

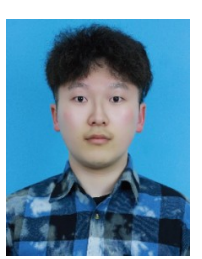

Minghao Liang received his BA degree from Changzhou University in 2019. He is currently a master student at the University of Electronic Science and Technology of China. His research focuses on the investigation of graphene growth by R2R CVD.

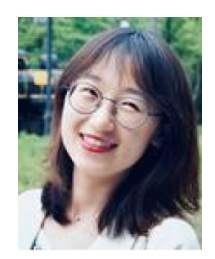

Yuting Hou received her BA degree from the University of Electronic Science and Technology of China in 2019. She is currently a $\mathrm{PhD}$ candidate at the University of Electronic Science and Technology of China. Her research focuses on graphene fabrication and applications.

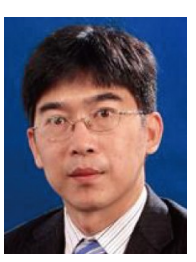

Xuesong Li received his $\mathrm{PhD}$ degree from Rensselaer Polytechnic Institute in 2007 . He is currently a professor at the University of Electronic Science and Technology of China. His research interests are synthesis and applications of CVD graphene.

\section{卷对卷化学气相沉积法制备石墨烯}

梁明吴 ${ }^{1,2}$, 钱凌轩 ${ }^{1,2}$, 侯雨婷 ${ }^{1,2^{*}}$, 李俊 ${ }^{1,2}$, 沈长青 1,2 , 青芳竹 ${ }^{1,2,3}$, 李雪松 $1,2,3^{*}$

摘要 批到批(B2B)和卷到卷 $(\mathrm{R} 2 \mathrm{R})$ 工艺均可用于石墨烯薄膜的大规模 生产. 由于设备简单, B2B工艺在实验室研究中非常普遍. 相对而言, R2R工艺更容易自动化, 并且与随后的转移过程更兼容, 因此在工业上 更受青睐. 目前, 对R2R工艺的研究主要集中在反应器设计或装料结构 等方面, 对石墨烯生长动力学缺乏深入的了解. 本文通过研究石墨烯的 生长演化过程, 发现在相同的反应参数下, R2R工艺的石墨烯晶畴密度 大于 $\mathrm{B} 2 \mathrm{~B}$ 工艺的石墨烯畴密度，其原因归结于两种工艺不同的反应过 程; 而通过延长反应时间, 可以对石墨烯薄膜的缺陷进行修复. 在优化 的R2R工艺下，可以获得与常规B2B工艺相当的高质量石墨烯薄膜. 本 工作可促进石墨烯薄膜制备技术的发展. 